\title{
Phytochemical Analysis, In-vitro Antioxidant and Anti-Hemolysis Activity of Turbinaria ornata (turner) J. Agardh
}

\author{
D. Vijayraja ${ }^{1}$ and $*$ Dr K. Jeyaprakash ${ }^{2}$ \\ Research and Development Centre, Bharathiar University, Coimbatore, Tamilnadu, India ${ }^{1}$ \\ *Corresponding Author, Head, Department of Biochemistry, PG and Research Department of Biochemistry, \\ Rajah Serfoji Government College, Thanjavur ${ }^{2}$
}

\begin{abstract}
The assault of free radicals and imbalance in oxidant and antioxidant status leads to the induction of diseases from cancers to neuro-degenerative diseases. Natural antioxidants can put a secured check over free radicals and the damages induced by them at various levels. Seaweeds are rich in bioactive compounds like sulfated polysaccharides, phlorotannins and diterpenes which are benefit for human health applications. Turbinaria ornata, the spiny leaf seaweed has been studied for its antioxidant, antiulcer, wound healing and hepatoprotective activities. In the present study, phytochemicals analysis, in vitro antioxidant and anti-hemolysis activity of Turbinaria ornata methanolic extract (TOME) in RBC model was done. The results reveal the presence of carbohydrates, alkaloids, saponins, phenolic compounds, flavonoids, tannins, coumarines, steroids and terpenoids. The UV-Vis, FTIR and GCMS analysis also elucidates the presence of phenolics and important bioactive compounds in TOME, which exhibits appreciable antioxidant activity and prevents $\mathrm{H}_{2} \mathrm{O}_{2}$ induced hemolysis in human $\mathrm{RBC}$ model by maintaining the cell membrane integrity.
\end{abstract}

Key words: Turbinaria ornata, invitro antioxidant avtivity, antihemolysis, bioactive compounds.

\section{INTRODUCTION}

Free radicals are playing adverse role in etiology of wide spectrum of diseases from cancers to neuro-degenerative diseases. They induce alterations in forms and function of various biological molecules to bring about the diseased conditions [1]. Oxidative stress is having prominent role in pathogenesis of cancer and several neurodegenerative diseases including Alzheimer's disease (AD), Parkinson's disease etc [2]. Reactive oxygen species (ROS) produced enormously due to endogenous and exogenous stimuli leads to induction of signal transduction that results in mitochondrial dysfunction and cell death [3]. Antioxidants can put a check over free radicals and the damages induced by them at various levels. A multipotent drug which has the ability to reduce the free radicals formation, good antioxidant capacity and membrane stabilizing potential is of great use in treating most of diseases [4]. Seaweeds are rich in bioactive compounds like sulfated polysaccharides, phlorotannins and diterpenes which are benefit for both human and animal health applications and are considered to be a rich source of antioxidants [5]. Turbinaria ornata, the spiny leaf seaweed has been studied for its anti-oxidant, antiulcer, wound healing and hepatoprotective activities[6]. In the present study the phytochemical screening, free radicals scavenging activity and antihemolytic activity of Turbinaria ornata have been investigated in search of new drug from natural bioactive compounds.

\section{MATERIALS AND METHODS}

Chemicals

Hydrogen peroxide, 1, 1-diphenyl-2-pricrylhydrazyl, gallic acid, and ascorbic acid were obtained from Himedia laboratory Ltd., Mumbai, India. All other chemicals were of reagent grade and organic solvents were of spectral grade.

Collection of samples

The marine brown alga Turbinaria ornata was collected by hand picking from the intertidal waters of the Mandapam coast (Longitude $78^{0} 8^{\prime} \mathrm{E}$, Latitude $9^{0} 17^{\prime} \mathrm{N}$ ) in the Gulf of Mannar during the month of May 2015 in the early hours. The algal material was identified and authenticated in BSI coimbatore, Tamilnadu and a voucher specimen was maintained in our research Laboratory (BSI/SRC/5/23/2015/Tech./1304), collected algal material was washed with sea water and then with fresh water and freed from sand, salts and epiphytes.

Preparation of seaweed extracts.

The dried seaweed samples $(25 \mathrm{~g})$ were milled and extracted using $250 \mathrm{ml}$ of various solvents such as ethanol, methanol and aqueous for $24 \mathrm{~h}$ by using Soxhlet apparatus. Each filtrate was concentrated to dryness under reduced pressure using rotary evaporator. The samples were lyophilized by using freeze dryer (Lark, Penguin Classic Plus, India) and stored in a refrigerator at $2-8^{\circ} \mathrm{C}$ for use in subsequent experiments.

Preliminary Phytochemical Screening.

Preliminary phytochemical screenings of three different extracts were carried out as per the standard protocols of Harborne [7].

UV-Vis and FTIR analysis of TOME

UV-Vis analysis was made by scanning in the range of 200-800 nm using Shimazdu spectrophotometer and 
characteristic peaks were detected [8]. Fourier transform infrared spectroscopy (FTIR) analysis was done with the solid samples of TOME [9]. Turbinaria ornata (10mg) were mixed with $100 \mathrm{mg}$ of dried potassium bromide (Kbr) and compressed to prepare as a salt disc. The disc was then read spectrophotometrically (Bio-Rad FTIR-40, USA). The frequencies of different components present in each sample were analyzed.

GC-MS analysis for phycochemical constituents

A high resolution mass spectrum equipped with a data system in combination with Gas Chromatography was used for the chemical analysis of seaweeds. The aqueous methanolic extract of Turbinaria ornata was examined for its chemical composition using GC-MS THERMO GC - TRACE ULTRA VER: 5.0, THERMO MS DSQ II. The DB 5 - MS capillary standard non - polar column, with dimension of $30 \mathrm{Mts}$, ID : $0.25 \mathrm{~mm}$, FILM : $0.25 \mu \mathrm{m}$ was used and injection volume was one micro litre. The extract was diluted in methanol and injected in the split mode. The carrier gas was helium and the flow rate was $1.0 \mathrm{ml} / \mathrm{min}$. The temperature was programmed to an oven temperature of $70^{\circ} \mathrm{C}$ raised to $260^{\circ} \mathrm{C}$ at $6^{\circ} \mathrm{C} / \mathrm{min}$. The run time was $40.50 \mathrm{~min}$. The chemical constituents were identified after comparison with the data available in the library search results attached to the GC-MS instrument.

\section{Total antioxidant activity}

The antioxidant activity of the seaweed extract was evaluated by the phosphomolybdenum method [10]. The assay is based on the reduction of molybdenum by the extract and subsequent formation of a green complex at acidic pH. $2 \mathrm{ml}$ extract was combined with $1 \mathrm{ml}$ of reagent solution ( $0.6 \mathrm{M}$ sulfuric acid, $28 \mathrm{mM}$ sodium phosphate and $4 \mathrm{mM}$ ammonium molybdate), methanol was used in place of sample as blank. The tubes containing the reaction solution were capped and incubated in water bath at $95^{\circ}$ for 90 minutes. After the samples were cooled to room temperature, the absorbance of the solution was measured at $635 \mathrm{~nm}$ using a spectrophotometer against blank. The antioxidant activity was expressed as an equivalent of gallic acid (mg GA/g dried extract). All the measurements were measured in triplicates.

In vitro Free Radical Scavenging Assay

TOME was screened for its free radical scavenging and antioxidant potential by the following assays 1, 1diphenyl-2-pricrylhydrazyl (DPPH) scavenging assay [11, 12], Nitric oxide (NO) scavenging assay [13], hydrogen peroxide scavenging assay [14], superoxide scavenging assay [15]. All these assays were carried out in triplicates and compared with ascorbic acid as a standard.

Antihemolytic study on human RBC:

To determine the effect of TOME on $\mathrm{H}_{2} \mathrm{O}_{2}$ induced hemolysis in the light of the previous study [16] with slight modifications, the following sets of spectrophotometric tubes (each four tubes) prepared:

Group I: Control tubes: Theses tubes were contained 1.0 $\mathrm{ml} \mathrm{RBC}$ suspension made to $4 \mathrm{ml}$ with normal saline.

Group II: TOME tubes: $1 \mathrm{ml}(100 \mu \mathrm{g} / \mathrm{ml})$ TOME was mixed with $1.0 \mathrm{ml}$ RBC suspension. Final volume was made to $4.0 \mathrm{ml}$ with normal saline
Group III: $\mathrm{H} 2 \mathrm{O} 2$ treated tubes: $8 \mathrm{mM} \mathrm{H}_{2} \mathrm{O}_{2}$ solution $(0.5 \mathrm{ml})$ was mixed with $1.0 \mathrm{ml} \mathrm{RBC}$ suspension and the final volume was made to $4.0 \mathrm{ml}$ with normal saline.

Group IV: $\mathrm{H}_{2} \mathrm{O}_{2}$ and TOME treated tubes: $1 \mathrm{ml}$ of $\mathrm{RBC}$ suspension treated with $0.5 \mathrm{ml}$ of $8 \mathrm{mM} \mathrm{H}_{2} \mathrm{O}_{2}$ solution and $1 \mathrm{ml}(100 \mu \mathrm{g} / \mathrm{ml})$ TOME of $0.5 \mathrm{ml}, 0.75 \mathrm{ml}$ and $1 \mathrm{ml}$. All the tubes were incubated at $37^{\circ} \mathrm{C}$ for $4 \mathrm{hr}$ with intermittent shaking. Absorbance of the supernatants was obtained after centrifuging the incubated tubes at 1000rpm for 10 minutes and read spectrophotometrically at $540 \mathrm{~nm}$. Percentage of hemolysis was calculated by the formula given below

Percentage of hemolysis $=$

Absorbance of individual tubes $\mathrm{X} 100$

Absorbance with 10036 hemolysis $\mathrm{X} 10$

Figures and Tables

\begin{tabular}{|l|l|c|c|c|}
\hline $\begin{array}{l}\text { S } \\
\text { No }\end{array}$ & $\begin{array}{l}\text { Phyto } \\
\text { chemicals }\end{array}$ & Aqueous & Ethanol & Methanol \\
\hline 1 & Carbohydrates & - & - & + \\
\hline 2 & Alkaloids & + & - & + \\
\hline 3 & Saponins & - & - & + \\
\hline 4. & $\begin{array}{l}\text { Phenolic } \\
\text { compounds }\end{array}$ & - & + & + \\
\hline 5. & Flavonoids & - & + & + \\
\hline 6. & Tannins & - & + & + \\
\hline 7. & Coumarines & - & + & + \\
\hline 8. & Proteins & - & - & - \\
\hline 9. & Steroids & - & + & + \\
\hline 10. & Anthroquinones & - & - & - \\
\hline 11. & Terpenoids & - & + & + \\
\hline
\end{tabular}

Table1. Phytochemical analysis of Turbinaria ornata extracts in different solvents
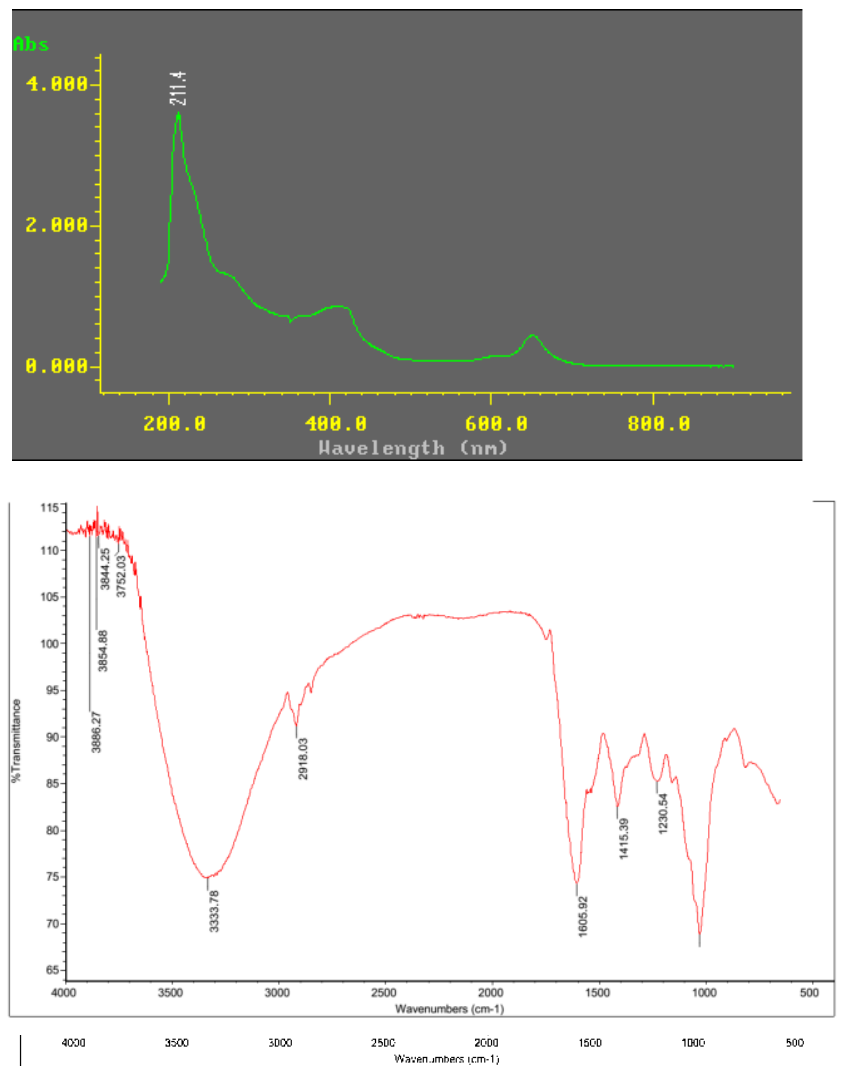
International Advanced Research Journal in Science, Engineering and Technology

Vol. 2, Issue 12, December 2015

Fig. 2 FTIR spectrum of TOME

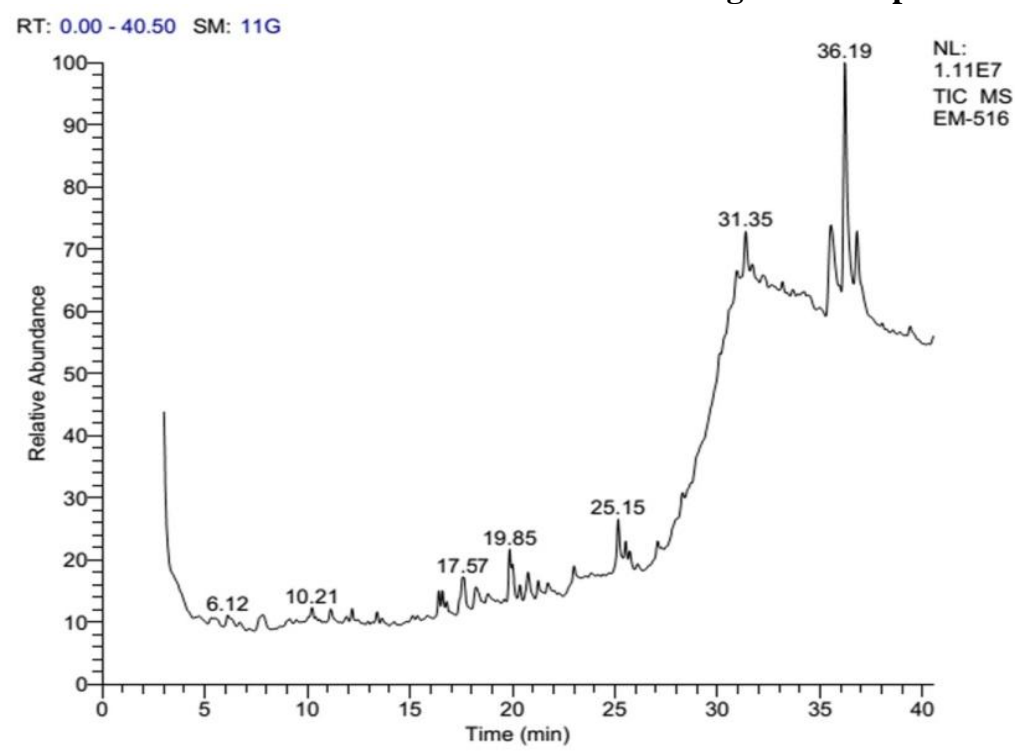

Fig.3. GC-MS Spectra of TOME

\begin{tabular}{|l|l|l|l|}
\hline $\begin{array}{l}\text { Retention } \\
\text { Time }\end{array}$ & Compound & Formula & $\begin{array}{l}\text { Molecular } \\
\text { weight }\end{array}$ \\
\hline 6.21 & trans-3-Chloro-1-isopropyl-2-(4-methylphenyl) azetidine & $\mathrm{C}_{13} \mathrm{H}_{18} \mathrm{ClN}$ & 223 \\
\hline 10.21 & 3-Acetyl-2-methyl-3a,4,5,8,9,9a-thexahydro-cyclooctafuran & $\mathrm{C}_{14} \mathrm{H}_{18} \mathrm{O}_{2}$ & 218 \\
\hline 17.57 & 1,1-Dimethyl-2-(1'-hydroxyethyl)-3,5bis(hydroxymethyl) cyclopentane & $\mathrm{C}_{11} \mathrm{H}_{22} \mathrm{O}_{3}$ & 202 \\
\hline 19.85 & Neophytadiene & $\mathrm{C}_{20} \mathrm{H}_{38}$ & 278 \\
\hline 25.15 & Phytol & $\mathrm{C}_{20} \mathrm{H}_{40} \mathrm{O}$ & 296 \\
\hline 31.35 & Di-(2-ethylhexyl) phthalate & $\mathrm{C}_{24} \mathrm{H}_{38} \mathrm{O}_{4}$ & 390 \\
\hline 36.19 & 2,6,10,14,18,22-Tetracosahexaene,2,6,10,15,19,23 hexamethyl- (CAS) & $\mathrm{C}_{30} \mathrm{H}_{50}$ & 410 \\
\hline
\end{tabular}

Table2. Phytochemical composition of TOME

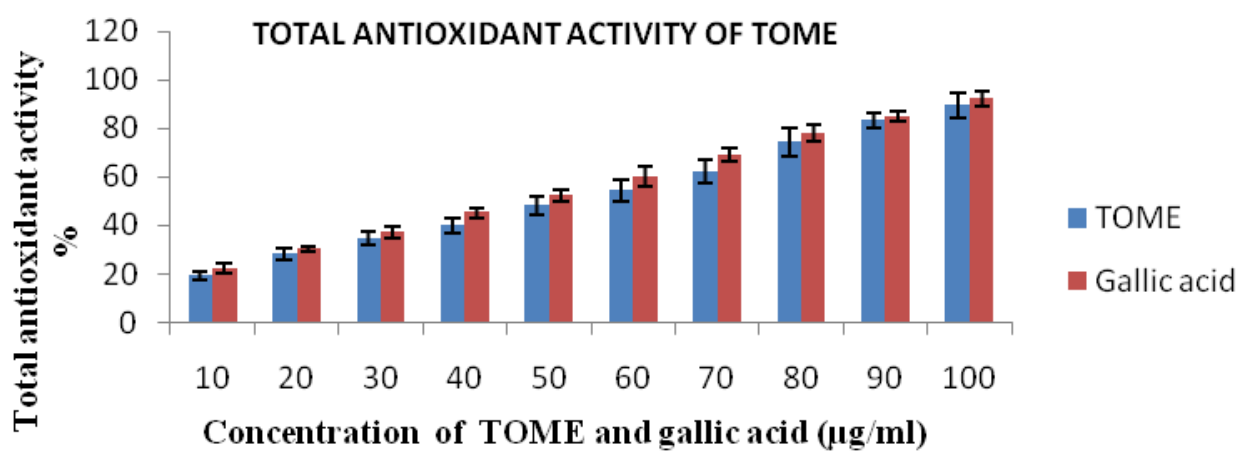

Fig. 4 Total antioxidant activity of TOME and gallic acid

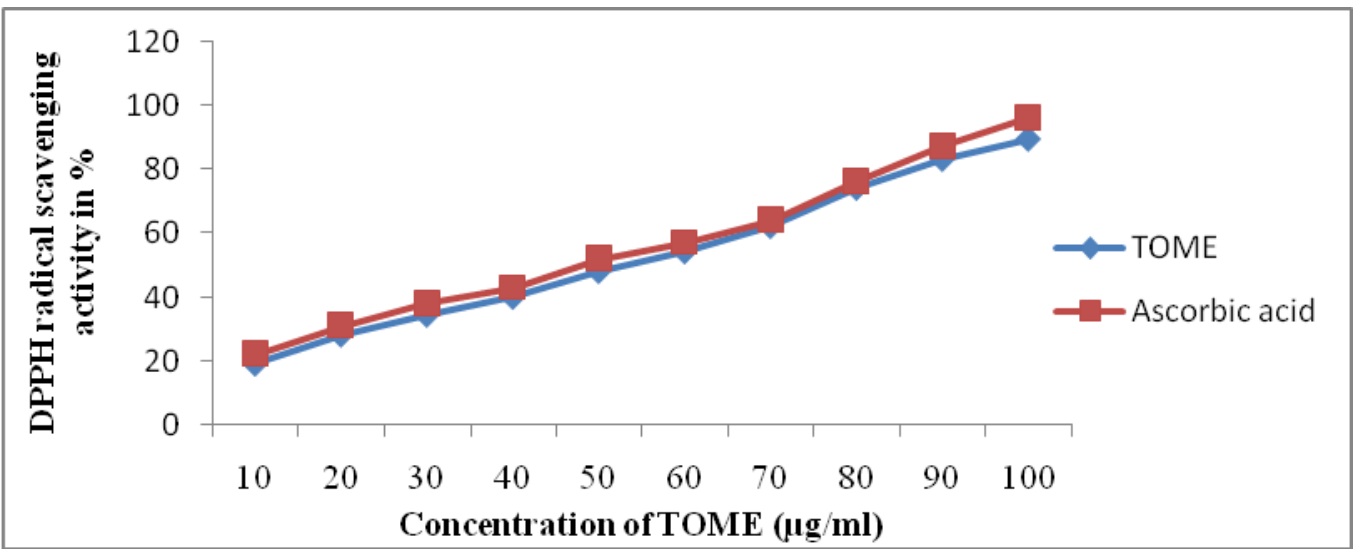


International Advanced Research Journal in Science, Engineering and Technology

Vol. 2, Issue 12, December 2015

Fig. 5 DPPH free radical scavenging activity of TOME and Ascorbic acid

\begin{tabular}{|c|c|c|c|c|c|c|}
\hline $\begin{array}{c}\text { Concentration } \\
\text { of } \\
\text { TOME/Ascorbic } \\
\text { acid } \boldsymbol{\mu g / m l}\end{array}$ & $\begin{array}{c}\text { NO } \\
\text { scavenging } \\
\text { capacity of } \\
\text { TOME } \\
(\boldsymbol{\%})\end{array}$ & $\begin{array}{c}\mathbf{H}_{\mathbf{2}} \mathbf{O}_{\mathbf{2}} \\
\text { scavenging } \\
\text { capacity of } \\
\text { TOME } \\
(\boldsymbol{\%})\end{array}$ & $\begin{array}{c}\text { SOD } \\
\text { scavenging } \\
\text { capacity } \\
\text { of TOME } \\
(\boldsymbol{\%})\end{array}$ & $\begin{array}{c}\text { NO } \\
\text { scavenging } \\
\text { capacity of } \\
\text { Ascorbic acid } \\
(\boldsymbol{\%})\end{array}$ & $\begin{array}{c}\mathbf{H}_{\mathbf{2}} \mathbf{O}_{\mathbf{2}} \\
\text { scavenging } \\
\text { capacity of } \\
\text { Ascorbic } \\
\text { acid }(\boldsymbol{\%})\end{array}$ & $\begin{array}{c}\text { SOD } \\
\text { scavenging } \\
\text { capacity of } \\
\text { Ascorbic } \\
\text { acid }(\boldsymbol{\%})\end{array}$ \\
\hline 10 & $22.46 \pm 2.24$ & $28.03 \pm 3.76$ & $14.03 \pm 3.28$ & $26.16 \pm 1.11$ & $32.09 \pm 2.67$ & $16.11 \pm 1.21$ \\
\hline 20 & $28.46 \pm 1.21$ & $34.46 \pm 4.20$ & $28.16 \pm 3.88$ & $33.16 \pm 2.18$ & $38.60 \pm 2.94$ & $32.10 \pm 2.71$ \\
\hline 30 & $35.22 \pm 2.18$ & $39.22 \pm 4.50$ & $32.12 \pm 4.18$ & $39.11 \pm 3.22$ & $43.11 \pm 3.21$ & $39.13 \pm 2.15$ \\
\hline 40 & $41.65 \pm 2.71$ & $41.65 \pm 4.93$ & $49.25 \pm 4.77$ & $44.35 \pm 1.21$ & $51.62 \pm 3.47$ & $52.35 \pm 2.27$ \\
\hline 50 & $47.27 \pm 5.09$ & $53.57 \pm 5.25$ & $53.33 \pm 5.09$ & $52.10 \pm 2.19$ & $59.13 \pm 2.12$ & $61.31 \pm 2.14$ \\
\hline 60 & $53.14 \pm 5.43$ & $58.80 \pm 5.74$ & $62.45 \pm 5.43$ & $57.24 \pm 1.23$ & $64.64 \pm 2.01$ & $67.18 \pm 2.32$ \\
\hline 70 & $58.11 \pm 3.24$ & $65.18 \pm 6.17$ & $69.11 \pm 2.69$ & $61.22 \pm 1.20$ & $70.92 \pm 2.12$ & $71.18 \pm 3.19$ \\
\hline 80 & $62.32 \pm 4.11$ & $71.60 \pm 6.61$ & $78.46 \pm 6.21$ & $67.12 \pm 1.21$ & $77.43 \pm 2.17$ & $82.21 \pm 5.21$ \\
\hline 90 & $68.25 \pm 2.37$ & $83.65 \pm 6.93$ & $81.58 \pm 4.77$ & $74.13 \pm 1.25$ & $89.93 \pm 3.11$ & $84.65 \pm 3.16$ \\
\hline 100 & $77.37 \pm 5.27$ & $89.57 \pm 7.33$ & $86.23 \pm 3.21$ & $79.37 \pm 3.11$ & $97.20 \pm 2.18$ & $89.57 \pm 7.17$ \\
\hline
\end{tabular}

Table3. In vitro free radical assay of TOME

\begin{tabular}{|c|c|c|c|c|}
\hline S.No & RBC Suspension $\mathbf{( 5 X 1 0} \mathbf{~} \mathbf{~ R B C} / \mathbf{m l})^{\mathbf{H}_{\mathbf{2}} \mathbf{O}_{\mathbf{2}} \text { Concentration }}$ & TOME 1 mg/1ml & Hemolysis \% \\
\hline Group 1 & $1 \mathrm{ml}$ & 0.0 & 0.0 & $0.11 \pm 0.01$ \\
\hline Group 2 & $1 \mathrm{ml}$ & 0.0 & $1 \mathrm{ml}$ & $0.12 \pm 0.02$ \\
\hline Group 3 & $1 \mathrm{ml}$ & $8 \mathrm{mM}$ & 0.0 & $93.75 \pm 7.50$ \\
\hline Group 4 & $1 \mathrm{ml}$ & $8 \mathrm{mM}$ & $0.5 \mathrm{ml}$ & $62.49 \pm 5.0$ \\
& $1 \mathrm{ml}$ & $8 \mathrm{mM}$ & $0.75 \mathrm{ml}$ & $32.47 \pm 2.60$ \\
& $1 \mathrm{ml}$ & $8 \mathrm{mM}$ & $1.00 \mathrm{ml}$ & $20.83 \pm 1.67$ \\
\hline
\end{tabular}

Table4. Ameliorative effect of TOME on hemolysis of RBC

\section{RESULTS AND DISCUSSION}

Phytochemical analysis of methanolic extract of Turbinaria ornata (TOME):

Table 1 shows the phytochemicals present in the aqueous, methanolic and ethanolic extracts of Turbinaria ornata. Methanolic extract of Turbinaria ornata (TOME) constitutes carbohydrates, alkaloids, saponins, phenolic compounds, flavonoids, tannins, coumarines, steroids and terpenoids our findings are supported by the earlier study [17], therefore TOME was chosen for further in vitro free radical scavenging effects.

UV-Vis and FTIR analysis of TOME

Figure.1 depicts the UV-VIS analysis of TOME, In UVVis spectra TOME extract exhibited good absorption at $214 \mathrm{~nm}$, this absorption maximum indicates the presence of phenolics which is a promising evidence for the antioxidant activity investigated in this study our results are well supported by the previous study [18]. Figure.2 depicts the FTIR analysis of TOME. The FTIR spectrum spectrum of TOME in the region 3995.85-455.13 constitutes the following bioactive compounds Chondroitin sulfate, Streptomycin sulfate, 6-deoxy-dglucose crystalline, Isomaltose, Limonene, 11-ketoetio cholanolone glucuronid , Kanamycin monosulfate 2fluoroethanol, Alpha-bromo-p-xylene, benzyl alcohol, p-nitrophenyl-b-d-mannopyranoside Pinacolone, Methyl alcohol , Silicone oil, Ristocetin sulfate, Ethylbenzyl alcohol, para-Toluenesulfonyl fluoride, Adenosine 5'diphosphoglucose butyramide . Alcohol: O-H (stretch, Hbonding) $3200-3600 \mathrm{~cm}^{-1}$, O-H Stretch, free 3500-3700 $\mathrm{cm}^{-1}$, C-O stretch 1050-1150 $\mathrm{cm}^{-1}$, Alkane: C-H stretch
2850-3000 $\mathrm{cm}^{-1}$, -C-H bending 1350-1480 $\mathrm{cm}^{-1}$, Alkene $=\mathrm{C}-$ Hstretch $3010-3100 \mathrm{~cm}^{-1}=\mathrm{C}-$ Hbending $675-1000 \mathrm{~cm}^{-}$

1, C=Cstretch 1620-1680 $\mathrm{cm}^{-1}$, Alkyne C-H stretch 3300 $\mathrm{cm}^{-1},-\mathrm{C}=\mathrm{C}-$ stretch $2100-2260 \mathrm{~cm}^{-1}$, Amines: N-H stretch $3300-3500 \mathrm{~cm}^{-1}$, C-H stretch 1080-1360 $\mathrm{cm}^{-1}, \quad \mathrm{~N}-\mathrm{H}$ bending $1600 \mathrm{~cm}^{-1}$, Aromatic : C-H stretch $3000-3100 \mathrm{~cm}^{-}$ 1 , C $=$ Cstretch 1400-1600 $\mathrm{cm}^{-1}$, Carbonyl $\mathrm{C}=$ Ostretch 1670-1820 $\mathrm{cm}^{-1}$, Nitro compounds: N-O stretch 15151560\&1345-1385 $\mathrm{cm}^{-1}$. IR ABSORPTION :Carbonyl $\mathrm{C}=$ Ostretch 1670-1820 $\mathrm{cm}^{-1}$, Acid: C=Ostretch 1700-1725 $\mathrm{cm}^{-1}$,O-H stretch 2500-3300 $\mathrm{cm}^{-1}$, C-O stretch 1210-1320 $\mathrm{cm}^{-1}$, Aldehyde: $\mathrm{C}=$ Ostretch $1740-1720 \mathrm{~cm}^{-1},=\mathrm{C}-\mathrm{H}$ stretch 2820-2850 and 2720-2750 $\mathrm{cm}^{-1}$, Amide: C=Ostretch 1640$1690 \mathrm{~cm}^{-1}$, N-H stretch $3100-3500 \mathrm{~cm}^{-1}$, N-H bending $1550-1640 \mathrm{~cm}^{-1}$. FTIR spectrum strongly elucidates the promising bioactive compounds in TOME the present study results well supported by the previous study [19].

GC- MS analysis: Figure. 3 elucidates the GC- MS analysis of crude methanolic extract of Turbinaria ornata showed the presence of mixture of bioactive compounds. A total of 7 peaks were observed with different retention times as presented in Fig. The molecular formula and molecular weight for the compounds identified were fetched from the library search results of the GC-MS systems and are given in Table 2, our results are well supported by the previous study [20].

Total antioxidant activity and free radical scavenging activity of TOME:

Figure. 4 shows the total antioxidant activity of TOME by phosphomolybdenum method, TOME at the concentration of $100 \mu \mathrm{g}$ shows $89.11 \%$ of total antioxidant activity as 
compared with the standard gallic acid which is supported by the previous reports [21]. Figure.5 shows the DPPH radical scavenging activity of TOME. DPPH is a stable radical and is widely used to evaluate antioxidant activities of bioactive substances. The antioxidant activity of a samples was carried out by measuring the absorbance of DPPH radical in the sample at $517 \mathrm{~nm}$ as against to that of control. The scavenging ability of TOME was concentration dependent. The TOME shows the greatest DPPH antioxidant activity $(\sim 80 \%)$ at $100 \mu \mathrm{g} / \mathrm{ml}$ [22]. TOME having appreciable DPPH radical scavenging activity. Table 3 depicts the free radical scavenging capacity of TOME and the standard ascorbic acid. Concentrations of TOME were chosen as per the earlier report [23], with slight modifications. The antioxidant properties of phenolics are as a result of their ability to act as reducing agents, hydrogen donors, and free radical quenchers. Phenolics can also act as metal chelators which prevent the catalytic function of metal in the process of initiating radicals. Also, it is reported that Turbinaria ornata have high phenolic content which is responsible for their respective antioxidant activity. The free radicals $\mathrm{NO}, \mathrm{H}_{2} \mathrm{O}_{2}$ and $\mathrm{SOD}$ scavenging activity are increased with increase in the concentration of TOME and the results are well supported by the previous study ${ }^{19}$. Hemolytic activity of TOME on human RBC:

Table 4 shows the hemolytic activity of TOME on human $\mathrm{RBC}$ hemolysis. The rupturing of RBC cells is known as hemolysis. Hemolysis is a good indicator of cytotoxicity. Hydrogen peroxide affects the integrity of the erythrocyte membrane. Thus Group III $\mathrm{H}_{2} \mathrm{O}_{2}$ treated shows high level hemolysis compared to control Group I. Group II TOME treated RBC models shows no significant hemolysis compared to Group III $\mathrm{H}_{2} \mathrm{O}_{2}$ treated which is similar to the earlier different study [24]. Whereas Group IV treated with different concentrations of TOME $(0.5 \mathrm{mg} / \mathrm{ml}, 0.75$ $\mathrm{mg} / \mathrm{ml}, 1 \mathrm{mg} / \mathrm{ml}$ ) and $\mathrm{H}_{2} \mathrm{O}_{2}$ treated shows significant reduction in hemolysis compared to Group III $\mathrm{H}_{2} \mathrm{O}_{2}$ treated. TOME maintains the stability of human red blood cell membrane also inhibits $\mathrm{H}_{2} \mathrm{O}_{2}$ assault $\mathrm{RBC}$ membrane.

\section{CONCLUSION}

In the present study preliminary phytochemicals, in vitro antioxidant activity analysis of methanolic extract of Turbinaria ornata (TOME) have been done and investigated further for its anti-hemolysis activity in RBC model of blood collected from healthy volunteers of 22-25 years age. The phytochemical analysis elucidates the presence of significant bioactive compounds in the methanolic extract of Turbinaria ornata, similarly the UVVis, FTIR and GCMS analysis elucidates the presence of bioactive compounds with potent antioxidant activity. Thus Turbinaria ornata with potent bioactive compounds shows appreciable antioxidant activity prevents $\mathrm{H}_{2} \mathrm{O}_{2}$ induced hemolysis in human $\mathrm{RBC}$ model by maintaining the cell membrane integrity. Further invivo studies, NMR assay, drug leads and molecular level investigations will be done to bring out the medicinal value of the Turbinaria ornata in treating different diseases due to the assault of free radicals and oxidative stress.

\section{REFERENCES}

1. Mariya V. and Vinoth S., 2013. Biomedical and Pharmacological significance of marine macro algae-review. Indian Journal of GeoMarine Sciences., 42(5):527-537.

2. Klein JA. and Ackerman SL., 2003. Oxidative stress, cell cycle, and neurodegeneration. J Clin Invest., 111(6):785-793.

Martindale JL. and Holbrook NJ., 2002. Cellular response to oxidative stress: signaling for suicide and survival. J Cell Physiol.,192 (1):1-15.

Yun-Zhong Fang, Sheng Yang, and Guoyao Wu., 2002. Free Radicals, Antioxidants, and Nutrition. Nutrition., 18:872- 879.

5. Cahyana AH., Shuto Y., Kinoshita Y., 1992. Pyropheophytin a as an antioxidative substance from the marine alga, Arame (Eisennia bicyclis). Biosci Biotechnol Biochem., 56:1533-1535.

6. Kulandhaisamy, Arul Senthil, Annappan Murugan, 2013. Antiulcer, wound healing and hepatoprotective activities of the seaweeds Gracilaria crassa, Turbinaria ornata and Laurencia papillosafrom the southeast coast of India. Brazilian Journal of Pharmaceutical Sciences, 49:669-678

7. Harborne., 1998. "Methods of extraction and isolation," in Phytochemical Methods. (Chapman\&Hall). 3:60-66.

8. Johnson M, Babu A, Janakiraman N, et al., 2012. Phytochemical studies on Laurencia obtusa (Hudson) Lamourux. International Journal of Biomedical and Advance Research; 3(4): 225-232

9. Selvaraju Meenakshi., Shanmugam Umayaparvathi., Muthuvel Arumugam., and Thangavel Balasubramanian. 2012. In vitroantioxidant properties and FTIR analysis of two seaweeds of Gulf of Mannar. Asian Pacific Journal of Tropical Biomedicine.,S66-S70

10. Prieto, CD., Calligaris, S., Celloti, E., Nicoli, MC. 1999. Antiradical properties of commercial cognacs assessed by the DPPH test. J of Agri Food Chem., 48:4241- 4245.

11. Blois, MS., 1958. Antioxidant determinations by the use of a stable free radical. Nature, 181:1199-1200.

12. Yen, GC., Duh, PD., Chuang, DY., 2000. Antioxidant activity of anthroquinones and anthrone. Food Chem., 70:437-441.

13. Gulcin, I., 2006. Antioxidant and antiradical activities of LCarnitine. Life Sciences. 78:803-811.

14. Gulcin, T., Irfan, KO, et al., 2004. Antioxidant, antimicrobial, antiuclcer and analgesic activities of nettle (Urtica dioica L.). J. Ethnopharmacol., 90:205-215.

15. Nishimiki, M., Rao, NA., Yagi, K., 1972. The occurrence of superoxide anion in the reaction of reduced phenazine methosulfate and molecular oxygen. Biochem Biophys Res Commun.,46:849-853.

16. Neeta mathuria., Ramtej jayram verma., 2007. Aflatoxin induced hemolysis and its amelioration by turmeric extracts and curcumin in vitro. Acta Poloniae Pharmaceutica - Drug Research., 64: (2):165-168.

17. John Peter Paul, J., Shridevi, S.D.K., 2013. Preliminary phytochemical analysis of Sargassum myriocystum J.Ag. and Turbinaria ornata (Turner) J.Ag. from the South east coast of Tamil Nadu. India Journal of Biochemical and Pharmaceutical Research., 2(3):37-43

18. Leonardo Tavares Salgado, Rodrigo Tomazetto et al., 2007. The influence of brown algae alginateson phenolic compounds capability of ultraviolet radiation absorption in vitro. Brazilian journal of oceanography. 55(2):145-154

19. Vijayabaskar, P., Shiyamala, V., 2012. Antioxidant properties of seaweed polyphenol from Turbinaria ornata (Turner) J. Agardh, 1848. Asian Pacific Journal of Tropical Biomedicine. S90-S98.

20. Neelamathi and Kannan, 2015. Screening and Characterization of Bioactive Compounds of Turbinaria Ornata from the Gulf of Mannar, India. International Advanced Research Journal in Science, Engineering and Technology. 2:49-54.

21. Ananthi, Gayathri, Chandronitha., Lakshmisundaram., Hannah., 2011. Free radical scavenging and anti-inflammatory potential of a marine brown alga Turbinaria ornata (Turner) J.Agardh. Indian Journal of Geo-Marine Sciences, 40:5:664-670.

22. Dharmesh R Chejara., Stalin Kondaveeti., Ramavatar Meena., Siddhanta, AK, 2014. Antioxidant activity and phytochemical analysis of a few Indian seaweed species. Indian Journal of GeoMarine Sciences, 43:4:507-518.

23. Kayalvizhi., Vasuki Subramanian., Sithranga Boopathy., Kathiresan., 2014. Antioxidant properties of brown seaweeds (Turbinaria ornata (Turner) J.Agardh, 1848 and Padina tetrastromatica (Hauck), Journal of Biotechnological Sciences., 2:1:29- 37.

24. Lakshmi, G., Smitha, N., et al., 2014. Phytochemical profile, In Vitro antioxidant and hemolytic activities of various leaf extract of Nymphaea nouchali linn: an in vitro study. Int $\mathrm{j}$ pharm pharm sci. 6:548-552. 